\title{
Arsenic Levels and Speciation from Ingestion Exposures to Biomarkers in Shanxi, China: Implications for Human Health
}

\author{
Jinli Cui, Jianbo Shi, Guibin Jiang, and Chuanyong Jing*
}

State Key Laboratory of Environmental Chemistry and Ecotoxicology, Research Center for Eco-Environmental Sciences, Chinese Academy of Sciences, Beijing 100085, People's Republic of China

\section{Supporting Information}

ABSTRACT: Chronic exposure to arsenic (As) threatens human health. To systematically understand the health risks induced by As ingestion, we explored water and diet contributions to As exposure, and compared As in biomarkers and the arsenicosis in a geogenic As area in China. In this study, high percentages of water (77\% of $n=131$ total samples), vegetables $(92 \%, n=120)$, cereals $(32 \%, n=25)$, urine $(70 \%, n=99)$, nails $(76 \%, n=176)$, and hair $(62 \%, n=61)$ contained As higher than the acceptable levels. Dietary As contributed $92 \%$ of the average daily dose (ADD) when the water As concentration was less than $10 \mu \mathrm{g} / \mathrm{L}$, for which 5 out of 30 examined participants were diagnosed with arsenicosis symptoms. The distinct positive correlation between $\mathrm{ADD}$ and As concentrations in urine, nails, and hair suggests different applicability for these biomarkers. Methylated As as the
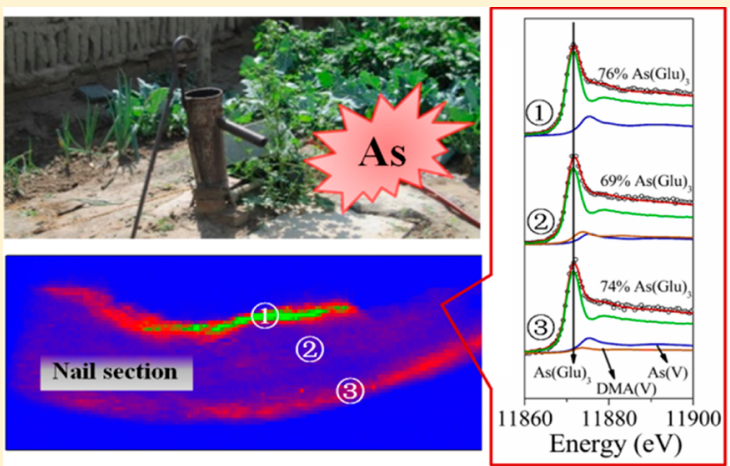
predominant urinary As species confirms that the ingested inorganic As is methylated and is excreted through urine. In situ microdistribution and speciation analysis indicates that As is mainly associated with sulfur in nails and hair. Nails, rather than hair and urine, could be used as a proper biomarker for arsenicosis. High ADD from the environment and low excretion could result in As toxicity to humans.

\section{INTRODUCTION}

Arsenic (As) poses a severe threat to human health through exposure pathways mainly including water and diet. ${ }^{1,2}$ Drinking water with elevated As levels is the primary source of As ingestion. ${ }^{1,3}$ Moreover, As-laden groundwater, if used for irrigation, can lead to appreciable amounts of As accumulation in vegetables and cereals. ${ }^{4-6}$ Extensive research demonstrates that rice and rice products could be another As source., However, not much attention has been paid to other cereals like wheat, which are important staple foods worldwide, that could lead to significant As ingestion.

The intake of As results in its detection in noninvasive human biomarkers such as urine, nails, and hair. ${ }^{10-12}$ Urine has frequently been used as a biomarker for short-term exposure because most As metabolites are excreted within 3-4 days through urine. ${ }^{12,13}$ Nails and hair indicate long-term exposure for 2-12 months, ${ }^{10}$ as As can be accumulated in these structures rich in keratin. ${ }^{14}$ Thus, the association of As levels in biomarkers and groundwater has been recently studied to evaluate its health risks. ${ }^{11,15}$

The speciation of As in biomarkers is crucial to understand the transformation, metabolism, and toxicity of ingested As. ${ }^{12,16}$ As species in hair and nails are traditionally determined by chemical extraction, where inorganic and methylated As are detected. $^{14,17}$ No As-S species have been reported using indirect chemical extraction methods, even though As readily bonds to sulphydryl groups. ${ }^{14}$ In contrast, As-S species have been detected in nail and hair samples using in situ X-ray absorption near-edge structure (XANES) spectroscopy. ${ }^{15}$ Unfortunately, methylated As species are not distinguished from the As-S form in nails, ${ }^{18}$ which deserves further exploration to understand the metabolism of As.

The purposes of this study were (1) to explore the contributions of water and diet to As exposure, and (2) to compare the As in biomarkers and the arsenicosis status in a geogenic As area in China. This comprehensive study should provide insights into As exposure and its health effects.

\section{MATERIALS AND METHODS}

Sample Collection. The study area lies in Shanyin, China, as described in our previous report. ${ }^{19}$ Groundwater from tube wells $(n=131)$, garden soils $(n=19)$, garden vegetables $(n=$ $120)$, cereals $(n=25)$, urine $(n=99)$, nails $(n=176)$, and hair ( $n=159)$ samples were collected, and the details of sample collection are given in the Supporting Information (SI). A total 222 of participants (male: 128; female: 94 ; age $\geq 17$ ) of approximately 7500 residents in 8 villages were asked to complete a self-administered questionnaire including age, sex, smoking habits, and duration of drinking groundwater. More

Received: January 9, 2013

Revised: April 18, 2013

Accepted: April 19, 2013

Published: April 19, 2013 
participants than water samples were surveyed because some participants share one tube well. The questionnaire results indicated that the residents in the study area mostly drink untreated groundwater. Dietary habits in the area were investigated in nine families as detailed in SI Table S10. Diagnosis for skin keratosis, depigmentation, and hyperpigmentation were based on the Chinese national standards for diagnosis of arsenicosis by trained interviewers. ${ }^{20}$

Sample Preparation and Analysis. Vegetables were washed with tap water to remove soil and dust particles, rinsed with deionized (DI) water, crushed, and dried at $60{ }^{\circ} \mathrm{C}$ for microwave digestion analysis. The cereal grains were crushed and dried for digestion. No As speciation was considered in vegetables and cereals, as inorganic As predominates in these samples. $^{4,7,9}$

Nail and hair samples were treated following a reported method. ${ }^{10}$ Briefly, nail and hair samples were washed in three steps, DI water-methanol-DI water, and then dried at $60^{\circ} \mathrm{C}$. Urine samples were centrifuged at $8000 \mathrm{rpm}$ for $10 \mathrm{~min}$, and the supernatant was filtered through a $0.22 \mu \mathrm{m}$ membrane for speciation analysis.

Solid samples were digested with a microwave digestion system (MARS, CEM Corporation, U.S.) as shown in the SI. The total As concentration was determined using an atomic fluorescence spectrometer (AFS, Haiguang, P.R. China) with a detection limit of $0.6 \mu \mathrm{g} / \mathrm{L}$. Groundwater samples were analyzed using a furnace atomic absorption spectrometer (FAAS, Perkin-Elmer AAS-800) with a detection limit of 0.7 $\mu \mathrm{g} / \mathrm{L}$.

Arsenite, arsenate, monomethylarsonic acid (MMA), and dimethylarsinic acid (DMA) in urine samples were determined using high-performance liquid chromatography (HPLC) coupled with AFS. The details of As speciation analysis are shown in the SI.

Quality Control. Standard reference materials (hair, GBW09101b; soil, GBW (E) 070011) were used to validate the microwave digestion analysis. A urine standard (GBW09115) was employed to justify the As speciation analysis by HPLC-AFS. Selected samples were digested and analyzed in duplicate or triplicate for quality control purposes. The relative standard derivation was calculated as an indication of method precision and was in the range of $85.4-117.5 \%$ (SI Table S3).

$\boldsymbol{\mu}$-XRF and $\boldsymbol{\mu}$-XANES Analysis. One nail and three hair samples were analyzed using $\mu$-XRF and $\mu$-XANES at beamline $15 \mathrm{U}$ at the Shanghai Synchrotron Radiation Facility (SSRF), China. The details of nail and hair preparation and analysis are shown in the SI. Standards including $\mathrm{Na}_{2} \mathrm{HAsO}_{4} \cdot 7 \mathrm{H}_{2} \mathrm{O}$, $\mathrm{NaAsO}_{2}, \mathrm{MMA}$, DMA, and arsenic-glutathione $\left(\mathrm{As}(\mathrm{Glu})_{3}\right.$ as detailed in the SI) were also analyzed and used in the linear combination fit.

Health Risk Assessment. A widely used model derived by the USEPA ${ }^{21}$ was applied to estimate the As impact on the residents in the study area. The As intake from water, vegetables, and cereals was considered using the following equation:

$$
\mathrm{ADD}=\mathrm{As}_{\mathrm{s}} \times \mathrm{IR} \times \mathrm{EF} \times \mathrm{ED} /(1000 \times \mathrm{AT} \times \mathrm{BW})
$$

where $\mathrm{ADD}$ is the average daily dose $(\mathrm{mg} / \mathrm{kg} / \mathrm{d}) ; \mathrm{As}_{\mathrm{s}}$ is the As concentration $(\mu \mathrm{g} / \mathrm{L}$ in groundwater; $\mu \mathrm{g} / \mathrm{g}$ in vegetables and cereals based on dry weight); IR is the ingestion rate (drinking water: $1.8 \mathrm{~L} / \mathrm{d}^{22}$ various vegetables and cereals: $\mathrm{g} / \mathrm{d}$ as shown in SI Table S10); EF is the exposure frequency (drinking water:
$365 \mathrm{~d} / \mathrm{y}$; food: values $(\mathrm{d} / \mathrm{y})$ calculated from questionnaire, SI Table S10); ED is the exposure duration (y) from the questionnaire; AT is the average life expectancy (25 550 day); ${ }^{23}$ and BW is the body weight (male: $61.0 \mathrm{~kg}$; female: $53.2 \mathrm{~kg}$ ). ${ }^{24}$

Toxic and cancer risk assessment was estimated using eqs 2 and 3, respectively:

$$
\mathrm{HQ}=\mathrm{ADD} / \mathrm{RfD}
$$

where $\mathrm{HQ}$ is the hazard quotient (toxic risk is considered occurring if $\mathrm{HQ}>1.00)$, $\mathrm{RfD}$ is the oral reference dose $(3 \times$ $\left.10^{-4} \mathrm{mg} / \mathrm{kg} / \mathrm{d}\right) ;^{21}$

$$
R=1-\exp (-\mathrm{SF} \times \mathrm{ADD})
$$

where $R$ is the cancer risk; $\mathrm{SF}$ is the slope factor $(1.5 \mathrm{mg} / \mathrm{kg} /$ d). ${ }^{21}$

\section{RESULTS AND DISCUSSION}

Arsenic in Groundwater, Vegetables and Cereals. An average As concentration of $174 \mu \mathrm{g} / \mathrm{L}(\mathrm{ND}-1160 \mu \mathrm{g} / \mathrm{L})$ was found in groundwater $(n=131)$, with $77 \%$ exceeding the WHO's guideline of $10 \mu \mathrm{g} / \mathrm{L}$ and $52 \%$ above $50 \mu \mathrm{g} / \mathrm{L}$ (Figure $1-\mathrm{I})$. Moreover, the average As(III) concentration $(114 \mu \mathrm{g} / \mathrm{L})$ was higher than $\mathrm{As}(\mathrm{V})(60.1 \mu \mathrm{g} / \mathrm{L})$, in line with the reducing conditions in the aquifer. ${ }^{25}$

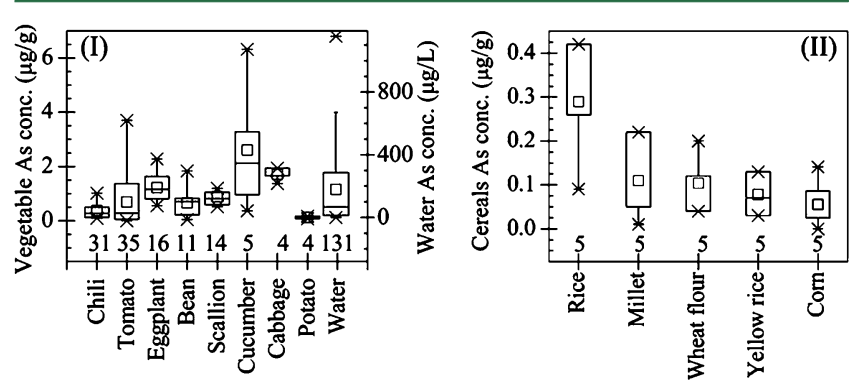

Figure 1. Boxplot of As contents in vegetables and groundwater samples (I) and cereals (II) with the sample numbers listed above the $x$-axis. The box represents the data between the 25th and 75th percentiles. The small box and horizontal line inside the box indicates the mean and median data. The whiskers (error bars) above and below the box indicate the 95th and 5th percentiles and dots above and below them represent outliers.

A range of As concentrations from ND to $6.0 \mu \mathrm{g} / \mathrm{g}$ was found in the edible part of the vegetable samples $(n=120$, Figure 1-I), with $92 \%$ exceeding the permissible limit in China $(0.05 \mu \mathrm{g} / \mathrm{g}){ }^{26}$ The average As content in the garden topsoil was $12.0 \mu \mathrm{g} / \mathrm{g}$, slightly higher than the background As level (5$10 \mu \mathrm{g} / \mathrm{g})$ in uncontaminated soils. ${ }^{25}$ Thus, As in vegetables should not be attributed to soils as evidenced by the lack of correlation between them (data not shown). Alternatively, a positive correlation was established between As contents in vegetables and irrigation water $(p=0.026$, SI Figure S6), suggesting As accumulation in vegetables from irrigation water. Although the eight categories of vegetables exhibited different As accumulation capacities (SI Figure S6), their As contents were higher than the reported data from other geogenic As sites (SI Table S11). For example, the As concentration was significantly higher than that in Spain $(0.05-0.93 \mu \mathrm{g} / \mathrm{g})$, probably due to the relatively low As concentrations in their irrigation groundwater $(14.8-280 \mu \mathrm{g} / \mathrm{L}) .{ }^{4}$ Moreover, a lower range of As in vegetables $(0.07-3.99 \mu \mathrm{g} / \mathrm{g})$ was found in Bangladesh with an average of $520 \mu \mathrm{g} / \mathrm{L}$ As in water. ${ }^{27}$ Thus, in 


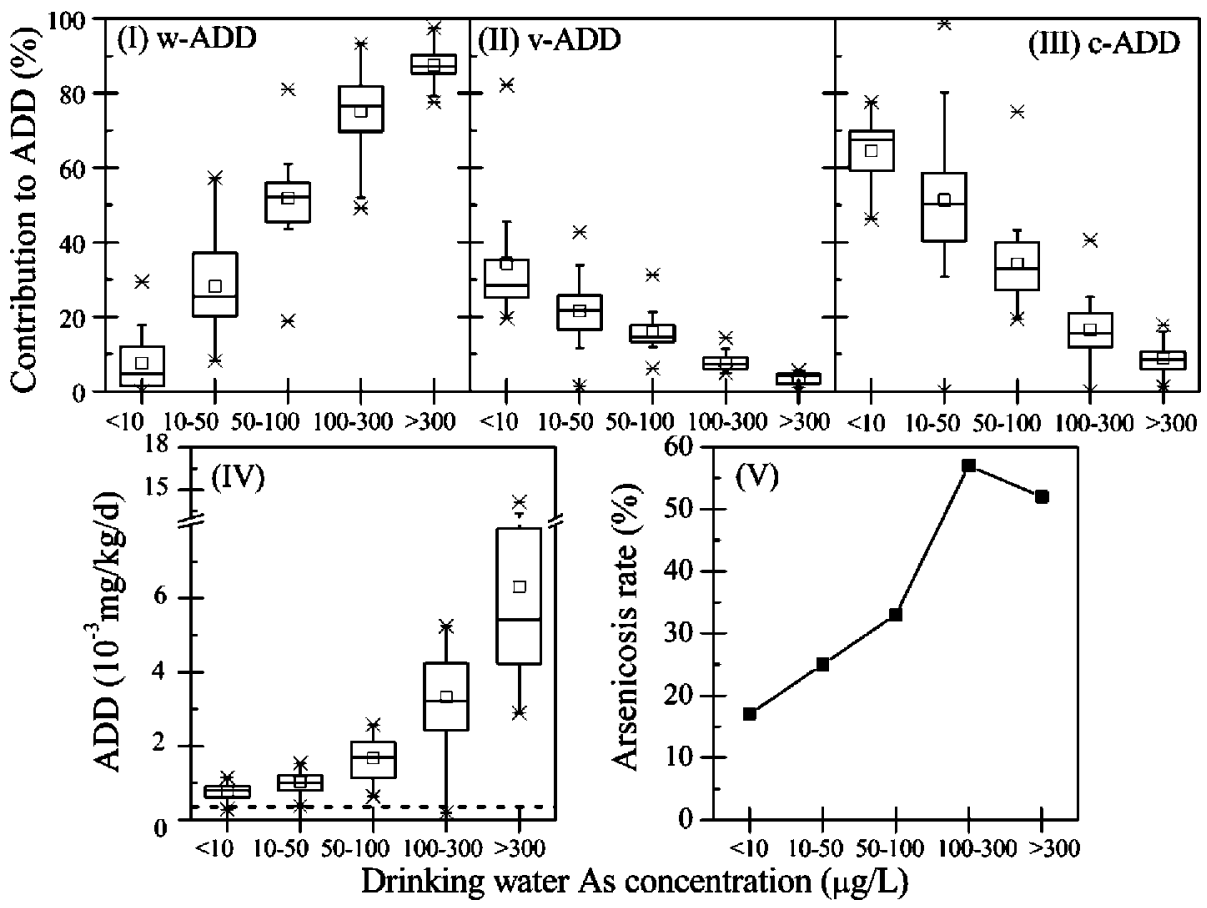

Figure 2. Percentage of contributions of drinking water (I, w-ADD), vegetables (II, v-ADD), and cereals (III, c-ADD) to ADD, total ADD (IV), and arsenicosis percentage (V) at different water As ranges: $<10(n=30), 10-50(n=28), 50-100(n=18), 100-300(n=30)$, and $>300(n=25) \mu \mathrm{g} /$ $\mathrm{L}$. The dashed line in (IV) represents oral reference dose (RfD, $\left.3 \times 10^{-4} \mathrm{mg} / \mathrm{kg} / \mathrm{d}\right)$ recommended by USEPA. The arsenicosis diagnosis was confirmed by examining the skin lesions like keratosis and pigmentation on the palms, soles, and body according to the standard of diagnosis for endemic arsenism in China. ${ }^{20}$

Table 1. Correlation Coefficients ${ }^{a}$ for Age, Sex, Arsenicosis ${ }^{b}, \mathrm{ED}^{c}, \mathrm{ADD}^{d}$ and from Water Drinking (w), Vegetables (v), Cereals (c), Ln (Urine As), Hair As, and Nail As

\begin{tabular}{|c|c|c|c|c|c|c|c|c|c|c|c|c|}
\hline & age & sex & $\begin{array}{c}\text { arseni- } \\
\text { cosis }\end{array}$ & $\begin{array}{c}\mathrm{ED}^{b}(\mathrm{w} \& \\
\mathrm{v})\end{array}$ & water As & $\mathrm{w}-\mathrm{ADD}^{c}$ & $\mathrm{v}-\mathrm{ADD}$ & $c-A D D$ & $\mathrm{ADD}$ & $\begin{array}{c}\ln (\text { ur-ine } \\
\text { As) }\end{array}$ & hair As & nail As \\
\hline age & 1 & 0.077 & 0.144 & $0.297 * *$ & -0.039 & 0.006 & $0.241^{* *}$ & $0.927 * *$ & $0.190 *$ & 0.016 & 0.083 & 0.117 \\
\hline sex & & 1 & -0.036 & -0.135 & 0.016 & 0.024 & 0.094 & $0.309^{* *}$ & 0.08 & -0.026 & -0.166 & 0.033 \\
\hline arsenicosis & & & 1 & 0.067 & $0.248^{* *}$ & $0.256^{* *}$ & 0.025 & $0.192^{*}$ & $0.285^{* *}$ & 0.143 & 0.199 & $0.269^{* *}$ \\
\hline $\mathrm{ED}(\mathrm{w}$ and $\mathrm{v})$ & & & & 1 & -0.084 & 0.147 & $0.814^{* *}$ & 0.146 & $0.186^{*}$ & 0.229 & $0.299^{* *}$ & $0.249^{*}$ \\
\hline water As & & & & & 1 & $0.950 * *$ & -0.081 & -0.03 & $0.888 * *$ & $0.292 *$ & $0.344^{* *}$ & $0.406^{* *}$ \\
\hline $\mathrm{w}-\mathrm{ADD}$ & & & & & & 1 & 0.138 & 0.009 & $0.951^{* *}$ & $0.36^{* *}$ & $0.343^{* *}$ & $0.416^{* *}$ \\
\hline $\mathrm{v}-\mathrm{ADD}$ & & & & & & & 1 & 0.142 & $0.187^{*}$ & $0.295^{*}$ & 0.071 & 0.15 \\
\hline$c-A D D$ & & & & & & & & 1 & $0.209^{*}$ & 0.037 & 0.051 & 0.142 \\
\hline $\mathrm{ADD}$ & & & & & & & & & 1 & $0.341^{*}$ & $0.328^{* *}$ & $0.412 * *$ \\
\hline $\begin{array}{l}\ln (\text { urine As) } \\
(57)\end{array}$ & & & & & & & & & & 1 & 0.225 & $0.429 * *$ \\
\hline hair As (96) & & & & & & & & & & & 1 & $0.605^{* *}$ \\
\hline nail As (95) & & & & & & & & & & & & 1 \\
\hline
\end{tabular}

${ }^{a}$ Correlation coefficient denoted as $p<0.05(*), p<0.01(* *)$ by Spearman analysis. ${ }^{b}$ Participants were divided into two populations with or without symptoms of arsenicosis. ${ }^{c} \mathrm{ED}$, exposure duration. ${ }^{d} \mathrm{ADD}$, average daily dose summing from groundwater $(\mathrm{w})$, vegetables (v), and cereals (c). The number of participants or samples is 131 otherwise noted in the bracket.

addition to the irrigation water, other factors including genetic difference in vegetables could contribute to the variation in As accumulation. ${ }^{4}$

The As concentrations in all cereals ranged from ND to 0.42 $\mu \mathrm{g} / \mathrm{g}(n=25$, Figure $1-\mathrm{II})$, with $32 \%$ of samples exceeding the permissible limit in China $(0.15 \mu \mathrm{g} / \mathrm{g}$ in rice, $0.1 \mu \mathrm{g} / \mathrm{g}$ in flour, and $0.2 \mu \mathrm{g} / \mathrm{g}$ in other cereals). ${ }^{26}$ The wheat flour, as the local staple food, was purchased from the market, and the average As concentration $(0.08 \mu \mathrm{g} / \mathrm{g})$ was a little higher than the flour samples $(0.021-0.054 \mu \mathrm{g} / \mathrm{g})$ collected from As-contaminated areas in France. ${ }^{9}$ Meanwhile, rice, as another staple food, was not locally planted and showed a mean concentration of 0.20 $\mu \mathrm{g} / \mathrm{g}$, within the upper end of the global background range $(0.082-0.202 \mu \mathrm{g} / \mathrm{g}){ }^{8}$ Low As concentrations were detected in nonstaple foods such as yellow rice $(0.10 \mu \mathrm{g} / \mathrm{g})$, corn $(0.06 \mu \mathrm{g} /$ $\mathrm{g}$ ), and millet $(0.06 \mu \mathrm{g} / \mathrm{g})$ (Figure 1-II), which are comparable to the reported data (SI Table S11).

Averaged Daily Dose for As Exposure. By summing the $\mathrm{ADD}$ from drinking water, vegetables, and cereals, the residents consumed a mean total ADD of $2.6 \times 10^{-3} \mathrm{mg} / \mathrm{kg} /$ day (range from 0.2 to $14.1 \mathrm{mg} / \mathrm{kg} /$ day, SI Table S7). Approximately $98.5 \%$ of $\mathrm{ADD}$ exceeded the $\mathrm{RfD}\left(3 \times 10^{-4} \mathrm{mg} / \mathrm{kg} /\right.$ day $){ }^{21}$ indicating a potentially hazardous risk of As ingestion. However, the $\mathrm{ADD}$ value was lower than that in Kandal, 
Cambodia $\left(3.5022 \times 10^{-3} \mathrm{mg} / \mathrm{kg} /\right.$ day on average $)$ where a higher average water As concentration of $846 \mu \mathrm{g} / \mathrm{L}$ was reported. $^{11}$

In addition to water, vegetables and cereals contributed a mean $\mathrm{ADD}$ value of $2.3 \times 10^{-4} \mathrm{mg} / \mathrm{kg} /$ day ( $2 \%$ exceeding the $\mathrm{RfD})$ and $5.0 \times 10^{-4} \mathrm{mg} / \mathrm{kg} /$ day (86\% exceeding the $\left.\mathrm{RfD}\right)$, respectively. Notably, the contribution of ADD from vegetables and cereals significantly increased with the decrease of water As concentrations (Figure 2-I, -II, and -III). For example, vegetables and cereals contributed $35 \%$ and $57 \%$ to $\mathrm{ADD}$, respectively, when As concentration was below $10 \mu \mathrm{g} / \mathrm{L}$ (Figure 2 ). In line with our results, the diet may contribute approximately $75 \%$ to the total $\mathrm{ADD}$ when the water As concentration is below $10 \mu \mathrm{g} / \mathrm{L}$.

A significant positive correlation was found between ADD and water As concentration $\left(r_{s}=0.888, p<0.001\right.$, Table 1$)$ and $\mathrm{ADD}$ indeed increased with water As levels (Figure 2-IV). Moreover, a positive correlation was observed between ADD and relevant parameters including age and exposure duration. Furthermore, chronic exposure through water and diet may lead to As accumulation in the human body, which could be confirmed by the analysis of noninvasive human biomarkers.

As Concentration and Speciation in Urine. The mean total urinary As concentration, calculated by summing As(III), As(V), DMA, and MMA, was $56.0 \mu \mathrm{g} / \mathrm{L}$ (ND-551 $\mu \mathrm{g} / \mathrm{L}, n=$ 99, Figure 3-I). The background As levels in urine are $10 \mu \mathrm{g} / \mathrm{L}$
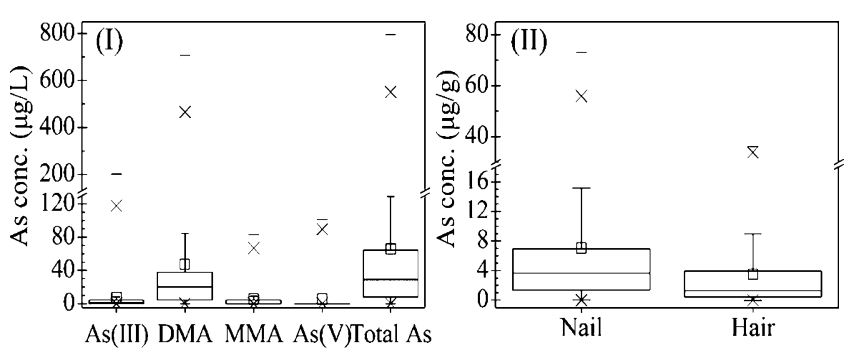

Figure 3. Speciation of As in urine (I, $n=99)$ and total As concentration in nails (II, $n=176$ ) and hair (II, $n=159$ ).

in European countries and the United States ${ }^{28}$ and $9.1 \mu \mathrm{g} / \mathrm{L}$ in the control adult group in Inner Mongolia, China. ${ }^{13}$ About $70 \%$ of the analyzed urine samples exceeded $10 \mu \mathrm{g} / \mathrm{L}$. Furthermore, Ln-transformed total urinary arsenic concentration increased with the increase in water As concentration $(p=0.029$, Table $1)$. For example, a mean urinary As concentration of $16.2 \mu \mathrm{g} / \mathrm{L}$ $(n=13)$ was detected in groups with $<10 \mu \mathrm{g} / \mathrm{L}$ As in drinking water, $45.4 \mu \mathrm{g} / \mathrm{L}(n=17)$ in groups with $10-50 \mu \mathrm{g} / \mathrm{L}$, and 110 $\mu \mathrm{g} / \mathrm{L}(n=34)$ in groups with $>50 \mu \mathrm{g} / \mathrm{L}$. A positive correlation was found between Ln-transformed total urinary arsenic and water $\operatorname{ADD}(p=0.006)$, vegetables $\operatorname{ADD}(p=0.027)$, and total ADD $(p=0.01)$ (Table 1). The outliers in Figure 3-I were due to five urine samples with high As concentrations. Higher As concentrations than $200 \mu \mathrm{g} / \mathrm{L}$ were observed in their drinking water, which contributed to such high urinary As concentrations.

DMA was the major As species in urine with a mean concentration of $42.6 \mu \mathrm{g} / \mathrm{L}$, followed by As(III) $(6.4 \mu \mathrm{g} / \mathrm{L})$, MMA $(5.9 \mu \mathrm{g} / \mathrm{L})$, and $\mathrm{As}(\mathrm{V})(4.8 \mu \mathrm{g} / \mathrm{L})$ (Figure3-I). The proportion of each species in urine (SI Table S4) was in agreement with a previous study ${ }^{29}$ and showed that methylated As species metabolized in the liver are preferentially excreted through urine.
As Concentration in Nails and Hair. The average As levels were $7.8 \mu \mathrm{g} / \mathrm{g}$ in nails $(n=176)$ and $4.2 \mu \mathrm{g} / \mathrm{g}$ in hair $(n=$ 159) (Figure 3-II). Approximately $76 \%$ of nail and $61 \%$ of hair samples exceeded the widely accepted background level of 1.5 $\mu \mathrm{g} / \mathrm{g}$ in nails ${ }^{10}$ and $1.0 \mu \mathrm{g} / \mathrm{g}$ in hair. ${ }^{30} \mathrm{~A}$ comparable study in India reported $7.2 \mu \mathrm{g} / \mathrm{g}$ As in nails and $3.4 \mu \mathrm{g} / \mathrm{g}$ As in hair with $62 \%$ of water samples exceeding $50 \mu \mathrm{g} / \mathrm{L}^{31}$ A positive correlation between concentrations in nails $(p<0.001)$ and hair $(p=0.001)$ with water As levels was found in this study (Table 1). Moreover, nails and hair, as biomarkers of long-term exposure, ${ }^{10}$ showed a positive correlation with total ADD (both $p<0.01$ ) and exposure duration (both $p<0.05$ ).

Microdistribution of Arsenic and Sulfur in Nails. The As content was higher in the margins than in the intermediate layer, as shown in the $\mu$-XRF image (Figure 4-I). As expected,

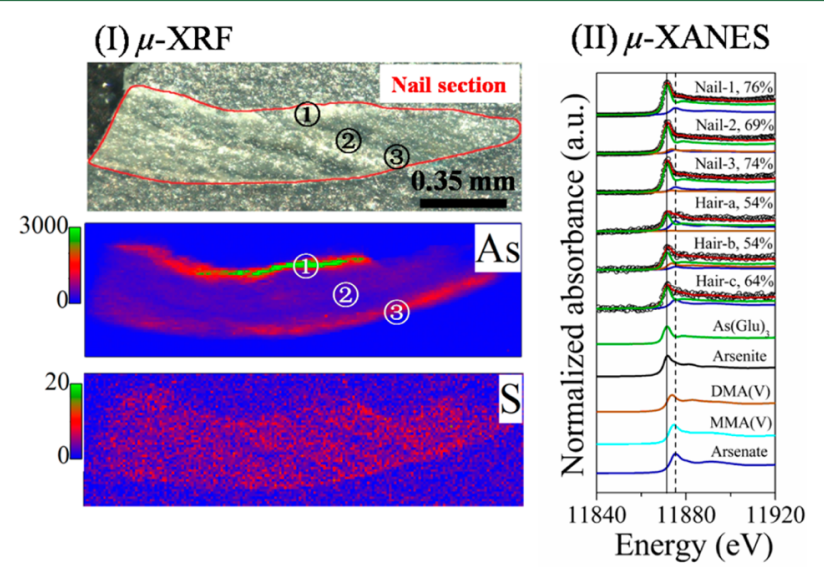

Figure 4. (I): Spatial distribution of As and $\mathrm{S}$ in a nail section (red outline) by $\mu$-XRF mapping (numbers 1 and 3 represent the margins and 2 represents the intermediate). (II): As K-edge $\mu$-XANES spectra of standards, one nail (three spots marked with numbers in (I), 73.1 $\mu \mathrm{g} \mathrm{As} / \mathrm{g})$ and three individual hair samples $(17.2 \mu \mathrm{g} / \mathrm{g}$ in a, $21.6 \mu \mathrm{g} / \mathrm{g}$ in $\mathrm{b}$, and $17.7 \mu \mathrm{g} / \mathrm{g}$ in $\mathrm{c}$ ). Experimental spectra are displayed as dashed lines. The red lines are the fit results; lines in different colors represent standard references. The solid and dashed vertical lines represent the $\mathrm{As}(\mathrm{Glu})_{3}$ and $\mathrm{As}(\mathrm{V})$ absorption edge, respectively. The inset percentages represent the $\mathrm{As}(\mathrm{Glu})_{3}$ proportion.

sulfur was homogeneously distributed among the sections because the nail is rich in keratin with sulphydryl groups. ${ }^{14}$ The free sulphydryl groups in the nail margins coordinate much more easily with inorganic As than the stable disulfide, which is rich in the intermediate layer. ${ }^{18}$ In accordance with our observations, discrete layers of As were reported in the nail samples collected from a gold mining area characterized by $\mu$ XRF mapping. ${ }^{18}$

Arsenic Speciation in Nails and Hair Using $\mu$-XANES. The dominant feature of nail and hair $\mu$-XANES spectra had an absorbance edge near As $(\mathrm{Glu})_{3}$ (Figure 4-II). The sulfur bonded As species (As-Glu) contributed $69-76 \%$ in nail and $54-64 \%$ in hair by linear combination fit (SI Table S6). The large content of As-Glu in these samples indicated that As bonds easily to the sulphydryl groups in keratin. ${ }^{14,17}$ Relatively more As-Glu was found in nails than in hair, corresponding to the higher keratin content in nails. ${ }^{17}$

DMA (18\%) was observed in the intermediate layer of nails (SI Table S6). The ingested As is primarily metabolized to a methylated form in the liver, which finally partially accumulates in the nails and hair. ${ }^{17,29}$ The nail is formed predominantly by the proximal nail matrix, where As is associated with free 
sulhydryl groups and is considered isolated from the metabolism during nail growth. ${ }^{32}$

Arsenic Risk Assessment and Health Implications. Significant positive correlations between ADD and Ln-transformed As concentrations in urine $\left(n=57, r_{\mathrm{s}}=0.341, p=\right.$ $0.01)$, nails $\left(n=96, r_{\mathrm{s}}=0.412, p<0.001\right)$, and hair $\left(n=95, r_{\mathrm{s}}=\right.$ 0.328, $p=0.001$ ) were obtained (Table 1). Thus, these biomarkers can reflect the As exposure with different retention times. Notably, severe patients were identified as deviations from the general association of As concentration in their biomarkers and ADD (Figure 5). A lung cancer patient marked
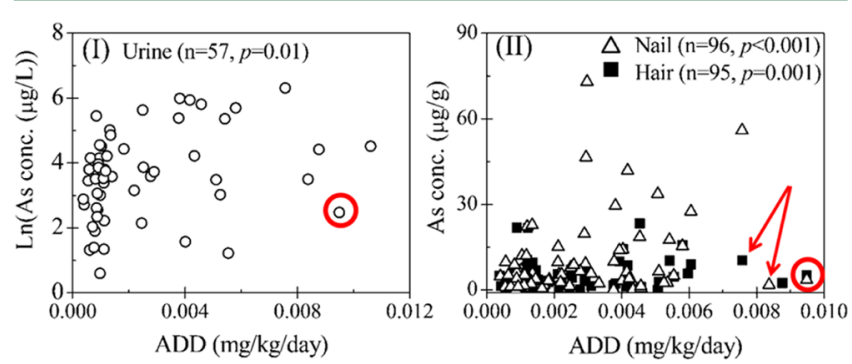

Figure 5. Correlation of $\mathrm{ADD}$ with arsenic concentrations in urine ( $p$ $=0.01$ using Ln-transformed urinary As concentration), nails ( $p<$ $0.001)$, and hair $(p=0.001)$.

with a red circle ingested substantially high $\mathrm{ADD}\left(1.5 \times 10^{-2}\right.$ $\mathrm{mg} \mathrm{As} / \mathrm{kg} /$ day) but excreted small quantities of As through urine $(11.9 \mu \mathrm{g} / \mathrm{L})$, nails $(3.6 \mu \mathrm{g} / \mathrm{g})$, and hair $(5.2 \mu \mathrm{g} / \mathrm{g})$. Meanwhile, two more patients labeled by arrows in Figure 5 are suffering from severe skin lesions. High $\mathrm{ADD}$ from the environment and low excretion due to metabolism might result in As toxicity to humans, although many factors including demographic characteristics, ${ }^{33}$ malnutrition, ${ }^{34}$ and individual health status ${ }^{11}$ may play a role.

The average HQ was 8.6 (0.6 to 47.1 ) with $98 \%$ of the residents exceeding the typical risk index of $1.00(n=131$, SI Tables S7 and 8). In addition, the mean cancer risk was about 4 in 1000 exposure $(n=131)$ and ranged from 4 in 10000 to 2 in 100 (SI Table S7). Meanwhile, the cancer risk was found to be $6 \%$ for $>1$ in 100 exposure, $88 \%$ for $>1$ in 1000 exposure, and $100 \%$ for highest safe standard of 1 in 10000 exposure (SI Table S8), which is in agreement with a previous study in Cambodia. ${ }^{11}$ Thus, exposure to As resulted in a severe health risk.

The arsenicosis rate increased with the increase in water As concentrations (Figure 2-IV). A similar result was obtained in Inner Mongolia, China, where a significant dose-response relationship was found between skin hyperkeratosis and water As concentrations. ${ }^{35}$ Moreover, $17 \%$ of examined participants with water As concentration below $10 \mu \mathrm{g} / \mathrm{L}(n=30)$ were diagnosed with arsenicosis symptoms. This observation was in agreement with previous reports. ${ }^{3,35}$ This extremely high rate can be attributed to the As intake from diet.

A significant correlation was observed between arsenicosis and nail As concentration $\left(r_{\mathrm{s}}=0.269, p<0.01\right.$, Table 1$)$. No correlation was observed between arsenicosis and Ln (urinary As) $\left(r_{\mathrm{s}}=0.143, p=0.295\right)$ and hair As concentrations $\left(r_{\mathrm{s}}=\right.$ $0.199, p=0.051)$. Thus, arsenicosis might be predicted by nail As concentration, even though an association was found between the As concentrations in these three biomarkers (Table 1). The observed arsenicosis status was not as severe as the estimated HQ results from the health risk assessment (SI
Table S7-8). However, we cannot wait for the development of arsenicosis to make any mitigation efforts because the As chronic toxicity symptoms are indeed time-lag effects. ${ }^{1,36}$

\section{ASSOCIATED CONTENT}

\section{S Supporting Information}

Details of sample collection; microwave digestion of soils, vegetables, cereals, nails, and hair samples; As speciation using HPLC-AFS; statistical methods; $\mu$-XRF and $\mu$-XANES sample preparation and analysis; and additional figures and tables. This material is available free of charge via the Internet at http:// pubs.acs.org.

\section{AUTHOR INFORMATION}

\section{Corresponding Author}

*Tel: +86 106284 9523; fax: +86 106284 9523; e-mail: cyjing@rcees.ac.cn.

\section{Notes}

The authors declare no competing financial interest.

\section{ACKNOWLEDGMENTS}

We acknowledge the financial support of the National Basic Research Program of China (2010CB933502) and the National Natural Science Foundation of China (20977098, 20890112, 41023005).

\section{REFERENCES}

(1) Berg, M.; Tran, H. C.; Nguyen, T. C.; Pham, H. V.; Schertenleib, R; Giger, W. Arsenic Contamination of Groundwater and Drinking Water in Vietnam: A Human Health Threat. Environ. Sci. Technol. 2001, 35, 2621-2626.

(2) Kile, M. L.; Houseman, E. A.; Breton, C. V.; Smith, T.; Quamruzzaman, O.; Rahman, M.; Mahiuddin, G.; Christiani, D. C. Dietary Arsenic Exposure in Bangladesh. Environ. Health Perspect. 2007, 115, 889-893.

(3) Ahsan, H.; Perrin, M.; Rahman, A.; Parvez, F.; Stute, M.; Zheng, Y.; Milton, A. H.; Brandt-Rauf, P.; van Geen, A.; Graziano, J. Associations between Drinking Water and Urinary Arsenic Levels and Skin Lesions in Bangladesh. J. Occup. Environ. Med. 2000, 42, 11951201.

(4) de la Fuente, C.; Clemente, R.; Alburquerque, J. A.; Velez, D.; Bernal, M. P. Implications of the Use of As-Rich Groundwater for Agricultural Purposes and the Effects of Soil Amendments on As Solubility. Environ. Sci. Technol. 2010, 44, 9463-9469.

(5) Dahal, B. M.; Fuerhacker, M.; Mentler, A.; Karki, K. B.; Shrestha, R. R.; Blum, W. E. H. Arsenic Contamination of Soils and Agricultural Plants through Irrigation Water in Nepal. Environ. Pollut. 2008, 155, $157-163$.

(6) Rahman, M. M.; Asaduzzaman, M.; Naidu, R. Consumption of Arsenic and Other Elements from Vegetables and Drinking Water from an Arsenic-Contaminated Area of Bangladesh. J. Hazard. Mater. 2012, DOI: 10.1016/j.jhazmat.2012.06.045.

(7) Halder, D.; Bhowmick, S.; Biswas, A.; Chatterjee, D.; Nriagu, J.; Guhamazumder, D. N.; Šlejkovec, Z.; Jacks, G.; Bhattacharya, P. Risk of Arsenic Exposure from Drinking Water and Dietary Components: Implications for Risk Management in Rural Bengal. Environ. Sci. Technol. 2012, DOI: 10.1021/es303522s.

(8) Zavala, Y. J.; Duxbury, J. M. Arsenic in Rice: I. Estimating Normal Levels of Total Arsenic in Rice Grain. Environ. Sci. Technol. 2008, 42, 3856-3860.

(9) Zhao, F.; Stroud, J. L.; Eagling, T.; Dunham, S. J.; McGrath, S. P.; Shewry, P. R. Accumulation, Distribution, and Speciation of Arsenic in Wheat Grain. Environ. Sci. Technol. 2010, 44, 5464-5468.

(10) Hinwood, A. L.; Sim, M. R.; Jolley, D.; de Klerk, N.; Bastone, E. B.; Gerostamoulos, J.; Drummer, O. H. Hair and Toenail Arsenic 
Concentrations of Residents Living in Areas with High Environmental Arsenic Concentrations. Environ. Health Perspect. 2003, 111, 187-193.

(11) Phan, K.; Sthiannopkao, S.; Kim, K.-W.; Wong, M. H.; Sao, V.; Hashim, J. H.; Yasin, M. S. M.; Aljunid, S. M. Health Risk Assessment of Inorganic Arsenic Intake of Cambodia Residents through Groundwater Drinking Pathway. Water Res. 2010, 44, 5777-5788.

(12) Mandal, B. K.; Ogra, Y.; Anzai, K.; Suzuki, K. T. Speciation of Arsenic in Biological Samples. Toxicol. Appl. Pharmacol. 2004, 198, 307-318.

(13) Sun, G.; Xu, Y.; Li, X.; Jin, Y.; Li, B.; Sun, X. Urinary Arsenic Metabolites in Children and Adults Exposed to Arsenic in Drinking Water in Inner Mongolia, China. Environ. Health Perspect. 2007, 115, 648-652.

(14) Raab, A.; Feldmann, J. Arsenic Speciation in Hair Extracts. Anal. Bioanal. Chem. 2005, 381, 332-338.

(15) Gault, A. G.; Rowland, H. A. L.; Charnock, J. M.; Woelius, R. A.; Gomez-Morilla, I.; Vong, S.; Leng, M.; Sarnreth, S.; Sampson, M. L.; Polya, D. A. Arsenic in Hair and Nails of Individuals Exposed to Arsenic-Rich Groundwaters in Kandal Province, Cambodia. Sci. Total Environ. 2008, 393, 168-176.

(16) Hughes, M. F. Arsenic Toxicity and Potential Mechanisms of Action. Toxicol. Lett. 2002, 133, 1-16.

(17) Mandal, B. K.; Ogra, Y.; Suzuki, K. T. Speciation of Arsenic in Human Nail and Hair from Arsenic-Affected Area by HPLCInductively Coupled Argon Plasma Mass Spectrometry. Toxicol. Appl. Pharmacol. 2003, 189, 73-83.

(18) Pearce, D. C.; Dowling, K.; Gerson, A. R.; Sim, M. R.; Sutton, S. R.; Newville, M.; Russell, R.; McOrist, G. Arsenic Microdistribution and Speciation in Toenail Clippings of Children Living in a Historic Gold Mining Area. Sci. Total Environ. 2010, 408, 2590-2599.

(19) Luo, T.; Hu, S.; Cui, J.; Tian, H.; Jing, C. Comparison of Arsenic Geochemical Evolution in the Datong Basin (Shanxi) and Hetao Basin (Inner Mongolia), China. Appl. Geochem. 2012, 27, 2315-2323.

(20) Standards for Diagnosis of Endemic Arsenism, WS/T 2000; Department of Public Health Standard Committee: Beijing, 2000.

(21) Integrated Risk Information System (IRIS): Arsenic, Inorganic, CASRN 7440-38-2; United State Environmental Protection Agency: Washington, DC, 1998.

(22) Schmitt, M. T.; Schreinemachers, D.; Wu, K.; Ning, Z.; Zhao, B.; Le, X. C.; Mumford, J. L. Human Nails As a Biomarker of Arsenic Exposure from Well Water in Inner Mongolia: Comparing Atomic Fluorescence Spectrometry and Neutron Activation Analysis. Biomarkers 2005, 10, 95-104.

(23) Li, G.; Sun, G. X.; Williams, P. N.; Nunes, L.; Zhu, Y. G. Inorganic Arsenic in Chinese Food and Its Cancer Risk. Environ. Int. 2011, 37, 1219-1225.

(24) Yang, X.; Li, Y.; Ma, G.; Hu, X.; Wang, J.; Cui, Z.; Wang, Z.; Yu, W.; Yang, Z.; Zhai, F. Study on Weight and Height of the Chinese People and the Differences between 1992 and 2002. Zhonghua Liuxingbingxue Zazhi 2005, 26, 489-493.

(25) Smedley, P. L.; Kinniburgh, D. G. A Review of the Source, Behaviour and Distribution of Arsenic in Natural Waters. Appl. Geochem. 2002, 17, 517-568.

(26) Maximum Levels of Contaminants in Foods, GB 2762-2005; The Ministry of Health: Beijing. 2005.

(27) Das, H. K.; Mitra, A. K.; Sengupta, P. K.; Hossain, A.; Islam, F.; Rabbani, G. H. Arsenic Concentrations in Rice, Vegetables, and Fish in Bangladesh: A Preliminary Study. Environ. Int. 2004, 30, 383-387.

(28) Cleland, B.; Tsuchiya, A.; Kalman, D. A.; Dills, R.; Burbacher, T. M.; White, J. W.; Faustman, E. M.; Marien, K. Arsenic exposure within the Korean Community (United States) Based on Dietary Behavior and Arsenic Levels in Hair, Urine, Air, and Water. Environ. Health Perspect. 2009, 117, 632-638.

(29) Vahter, M. Genetic Polymorphism in the Biotransformation of Inorganic Arsenic and Its Role in Toxicity. Toxicol. Lett. 2000, 112, 209-217.

(30) Hindmarsh, J. T. Caveats in Hair Analysis in Chronic Arsenic Poisoning. Clin. Biochem. 2002, 35, 1-11.
(31) Samanta, G.; Sharma, R.; Roychowdhury, T.; Chakraborti, D. Arsenic and Other Elements in Hair, Nails, And Skin-Scales of Arsenic Victims in West Bengal, India. Sci. Total Environ. 2004, 326, 33-47.

(32) Slotnick, M. J.; Nriagu, J. O. Validity of Human Nails As a Biomarker of Arsenic and Selenium Exposure: A Review. Environ. Res. 2006, 102, 125-139.

(33) Parvez, F.; Chen, Y.; Argos, M.; Hussain, A.; Momotaj, H.; Dhar, R.; van Geen, A.; Graziano, J. H.; Ahsan, H. Prevalence of Arsenic Exposure from Drinking Water and Awareness of Its Health Risks in a Bangladeshi Population: Results from a Large PopulationBased Study. Environ. Health Perspect. 2006, 114, 355-359.

(34) McCarty, K. M.; Houseman, E. A.; Quamruzzaman, Q.; Rahman, M.; Mahiuddin, G.; Smith, T.; Ryan, L.; Christiani, D. C. The Impact of Diet and Betel Nut Use on Skin Lesions Associated with Drinking-Water Arsenic in Pabna, Bangladesh. Environ. Health Perspect. 2006, 114, 334-340.

(35) Mo, J. Y.; Xia, Y. J.; Wade, T. J.; Schmitt, M.; Le, X. C.; Dang, R H.; Mumford, J. L. Chronic Arsenic Exposure and Oxidative Stress: OGG1 Expression and Arsenic Exposure, Nail Selenium, And Skin Hyperkeratosis in Inner Mongolia. Environ. Health Perspect. 2006, 114, 835-841.

(36) Smith, A. H.; Lopipero, P. A.; Bates, M. N.; Steinmaus, C. M. Arsenic Epidemiology and Drinking Water Standards. Science 2002, $296,2145-2146$. 